\title{
PEDAGOGIA EMPRESARIAL: UM ESTUDO SOBRE AS PRÁTICAS PARA A EXCELÊNCIA ORGANIZACIONAL
}

\section{ARTIGO ORIGINAL}

WERNECK, Jaqueline dos Santos Machado de Oliveira ${ }^{1}$

BARBOSA, Sidney ${ }^{2}$

WERNECK, Jaqueline dos Santos Machado de Oliveira. Pedagogia Empresarial: Um estudo sobre as práticas para a excelência organizacional. Revista Científica Multidisciplinar Núcleo do Conhecimento. Ano 05, Ed. 05, Vol. 01, pp. 75-92. Maio de 2020. ISSN: 2448-0959,

Link de

acesso: https://www.nucleodoconhecimento.com.br/pedagogia/excelenciaorganizacional

\section{RESUMO}

Este trabalho teve por objetivo ressaltar a importância da contribuição do pedagogo na empresa, descrevendo como esse profissional pode aplicar estratégias e processos que alcancem os resultados esperados. Torna-se evidente identificar as práticas aplicadas e desenvolvidas pelo pedagogo, pois a realidade das empresas atuais evidencia a presença da competitividade de mercado e mudanças cada vez mais velozes no contexto social, econômico, tecnológico, entre outros que interferem diretamente no andamento e nos processos empresarias. Logo, a busca por profissionais, que possam melhorar o desempenho e contribuir para uma prática de excelência no interior das organizações, é imprescindível. O pedagogo é um

${ }^{1}$ Graduada em pedagogia pela Uniabeu Centro Universitário - Nilópolis/RJ (2007), pós graduada em pedagogia empresarial e em administração e finanças na UNINTER. ${ }^{2}$ Graduado em Pedagogia. Especialista em Pedagogia Empresarial e Magistério Superior. Orientador da UNINTER. Atuação Profissional em Treinamentos, Supervisão e Coordenação Pedagógica. 
profissional importante para esses desafios. O contexto deste artigo apresenta informações sobre o início da inserção do pedagogo nas empresas, em sequência, a relação dele com esse meio corporativo; o perfil esperado desse profissional e exemplos de práticas que possam ser aplicadas e desempenhadas para 0 alcance dos objetivos almejados. Para melhor entendimento, acerca dos assuntos expostos, foram realizadas pesquisas bibliográficas relevantes, resultando em esclarecimentos pertinentes sobre a importante atuação do pedagogo no ambiente empresarial.

Palavras-Chave: Pedagogia empresarial, excelência, gestão de pessoas, práticas.

\section{INTRODUÇÃO}

As novas tecnologias, suportes modernos e digitais podem expressar grandes vantagens competitivas para o meio empresarial, porém dificilmente substituirá a capacidade humana, pois é por intermédio dela que a prática ocorre.

É relevante a atuação do pedagogo na integração desse processo, pois possui habilidades relacionadas às ações de melhoria no ambiente do trabalho que envolve as relações humanas. Ultimamente as empresas percebem a influência educativa no dia a dia de sua rotina.

O Pedagogo tem como princípio auxiliar nesse contexto, com práticas que buscam melhorar o rendimento e o desempenho dos profissionais com os quais ele atuará ou o setor da empresa que estará à frente. Ademais, Ribeiro (2007) destaca que a Pedagogia Empresarial se ocupa com os conhecimentos, as competências, habilidades e as atitudes como indispensáveis e necessárias à uma melhor produtividade.

Uma característica importante do Pedagogo é a facilidade em ser criativo e inovador, para o alcance de ações mais estratégicas e assertivas. A maneira de conduzir sua prática não se restringe em algo específico e estático, e sim amplo, diversificado e complexo. Ainda Ribeiro (2007), explica que o Pedagogo na empresa necessita de sensibilidade suficiente para perceber quais estratégias podem ser usadas. 
Reconhecer as ações do Pedagogo e adquirir conhecimentos relevantes sobre como são aplicadas as suas habilidades, será apresentado neste trabalho.

No decorrer deste artigo, serão expostas informações relevantes sobre a inserção desse profissional, o qual foi ganhando espaço no meio corporativo a partir de suas especificidades; a importância das características relacionadas ao que o Pedagogo pode empregar e contribuir; o perfil esperado para uma atuação coesa e flexível para estar diante das diferentes situações e práticas desenvolvidas.

Ao identificar as práticas apresentadas, é pertinente ressaltar a importante relação com a área de gestão de Pessoas, sendo inevitável essa ligação. Nesta área são aplicadas ações que estão ao encontro das potencialidades e atributos que o pedagogo possui. Portanto, serão exemplificadas algumas práticas: gestão por competências, planejamento de pessoal, Seleção, processos de treinamento, jogos empresarias e dinâmicas.

Logo, as pesquisas, o estudo e a concretização deste artigo contemplam o conhecimento acerca de como os processos da Pedagogia, e que são aplicáveis pelo pedagogo, podem contribuir para o alcance de resultados de sucesso e excelência nas empresas.

\section{PEDAGOGIA E EMPRESA}

A pedagogia foi, ao longo do tempo, considerada uma área importante somente para o ambiente escolar. Métodos e estratégias pedagógicas contribuíram e ainda contribuem para as práticas escolares que envolvem o corpo docente e discente. A pedagogia titula o pedagogo como o profissional que está à frente das características que essa área se aplica.

Contudo, a atuação do pedagogo está intimamente ligada à relação com pessoas. Assim, a pedagogia passou a ser vista como uma importante área a ser utilizada e aplicada em outros contextos, tais qual no meio empresarial. 
O pedagogo é o profissional que atua em várias instâncias da prática educativa, direta ou indiretamente ligadas à organização e aos processos de transmissão e assimilação ativa de saberes e modos de ação, tendo em vista a formação humana definida em sua contextualização histórica (LIBÂNEO,1998, p.25).

Logo é possível, segundo o autor, enfatizar a importância desse profissional com meios de ação que envolvem a formação humana e essa especificidade pode contribuir para as organizações além de outros ambientes profissionais.

O termo pedagogia empresarial surgiu no início da década de 1970, um período de mudanças nas estruturas empresariais, que gradualmente foram se reestruturando conforme as necessidades do meio social daquela época.

O período marcado em que o pedagogo na empresa se tornou efetivamente presente, foi pela necessidade de treinamentos e desenvolvimento de pessoas nas organizações. Dessa forma, Holtz (1999) ressalta que desde 1976, ao fundar a $\mathrm{MH}$ Assessoria e Treinamento, hoje MH Assessoria Empresarial, iniciou algumas atividades de treinamento e consultorias empresariais, adotando uma postura pedagógica, porém sem utilizar pacotes prontos de treinamento ou de reorganização. Seus programas de ação sempre visaram à orientação, o aperfeiçoamento e o estímulo das faculdades humanas.

De acordo com a autora, a descoberta do pedagogo, como profissional empresarial, foi por meio da necessidade de treinamentos e o desenvolvimento de pessoas. Tais processos atendiam as necessidades daquela época.

Esse período apresentou alguns conflitos diante dos novos rumos em que as indústrias, em expansão, conduziam as pessoas com suas respectivas funções, levando a necessidade de se criar, segundo Chiavenato (2016), uma Administração de Pessoal.

Logo, "as transformações ao longo do tempo conduziram as empresas a uma visão de administração de recursos humanos tendo maior preocupação com a motivação e 
com o desenvolvimento de seus colaboradores (...)” (KNAPIK, 2012, p. 51). Assim é válido ressaltar as informações de HOLTZ, que enfatiza o início da presença do Pedagogo nos espaços das organizações, com a finalidade de contribuir para sanar as dificuldades encontradas nesse momento histórico da década de 70.

E o termo pedagogia empresarial foi evidenciado, nesse período de reestruturação da área de Recursos humanos, com uma visão sendo ampliada para as pessoas que compõem os diferentes setores das empresas, e que passou a designar as atividades de incentivo ao desenvolvimento profissional e pessoal que ocorre dentro das organizações.

Logo, a partir de 1980 a busca do pedagogo para a prática com o processo de treinamento, entre outros, foram ganhando uma amplitude maior, pois aos poucos e pelas mudanças em vários setores sociais, econômicos entre outros, a atuação do Pedagogo foi alcançando maior visibilidade.

Ao complementar o exposto, Ribeiro (2007) aponta que o pedagogo começou a ser selecionado para atuar nas empresas no final da década de 1960, em razão da aceleração do desenvolvimento econômico e os progressos decorrentes da sociedade. Diante de tal informação, este autor aponta como mais antiga a atuação desse profissional, ou seja, o Pedagogo alcançou o espaço empresarial bem antes do que cita Holtz (1999).

As empresas, a partir de 1990, com os avanços tecnológicos; com o mundo globalizado e exigências cada vez maiores em relação a competitividade, buscavam por novas estratégias empresariais e se colocavam como imprescindíveis, por conseguinte o pedagogo foi se titulando como profissional a atuar na busca dos objetivos apontados no meio empresarial.

No atual século XXI, esse profissional contribui para o bom desempenho dos colaboradores que compõe a estrutura de uma organização, cooperando para o aumento da produtividade e organizando meios para o alcance do sucesso empresarial. Lopes (2007) afirma que: 
A Pedagogia Empresarial existe, portanto, para dar suporte tanto em relação à estruturação das mudanças quanto em relação à ampliação e à aquisição de conhecimento no espaço organizacional. $O$ pedagogo empresarial "promove a reconstrução de conceitos básicos, como criatividade, espírito de equipe e autonomia emocional e cognitiva. (LOPES, 2007, p. 74).

Diante desse contexto, o Pedagogo e a empresa podem ter uma relação de parceria para que se alcancem os objetivos almejados, visto que as empresas buscam profissionais que possam contribuir com excelência nos resultados de sucesso. $O$ Pedagogo que ingressa nessa missão, se ajusta e se insere nas exigências cada vez mais presentes do espaço corporativo. Contudo Lotz e Burda (2015) abordam que as organizações necessitam de recursos materiais e financeiros, energia, tecnologia e, principalmente, de pessoas e que por meio dessas pessoas que as organizações se criam, se estabelecem e se diferenciam.

Em contrapartida, o pedagogo ao ingressar em uma organização deve buscar a sua melhor atuação como colaborador capacitado e dedicado, já que a competitividade é percebida diante do mercado de trabalho. Assim, Scatena (2012) reitera a continua necessidade do profissional de pedagogia aprender, acumular conhecimento, criar ideias, oferecendo à empresa uma capacitação técnica aliada à sua forma de trabalhar.

\subsection{A IDENTIDADE DO PEDAGOGO EMPRESARIAL}

Toda profissão perpassa por mudanças, pois acompanha os avanços da realidade social, cultural, econômica entre outros enfoques. Com o Pedagogo não foi diferente e foi além, alcançou uma amplitude para se atuar, como em espaços não escolares. Logo, ele aponta a possibilidade de desenvolver práticas e que estas vêm contribuindo de maneira produtiva nos espaços que esse profissional é inserido e assim moldando sua própria identidade. Dessa forma, Pimenta (1999) aponta: 
A identidade do profissional se constrói, pois, a partir de significações sociais; da revisão constante dos significados sociais da profissão; da revisão constante dos significados e da profissão, da revisão das tradições. Mas também na reafirmação de práticas consagradas culturalmente e que permanecem significativas. (PIMENTA, 1999, p.19).

Entretanto, estabelecer uma identidade específica para o Pedagogo é um desafio, já que sua atuação diversificada, ampla e complexa, não define uma única atuação. É o que conclui Libâneo (1999) ao afirmar que o campo de atuação do pedagogia é tão vasto quanto são as práticas educativas na sociedade.

Logo, o pedagogo na empresa não possui uma identidade clara, pois a partir da aplicação das práticas que vão sendo desenvolvidas e como tais práticas vão se firmando e ganhando legitimidade, formam assim uma estruturação deste profissional. Ademais descreve Dubar (2005) que a identidade não é fornecida e sim construída e (re)construída em uma incerteza maior e mais ou menos duradoura.

Existe uma base para moldar a identidade do pedagogo que são métodos, processos e estratégias pedagógicas, ou seja, uma titulação a partir do que apresenta a Pedagogia, como um profissional que explora e desenvolve meios estratégicos educacionais para atuar de maneira significativa.

O meio empresarial contribui para a construção dessa identidade à medida que ele vai se firmando nesse ambiente empresarial, aplicando suas ações.

O Pedagogo é um profissional que atua conforme as necessidades apresentadas no meio em que é contratado, não possui uma identidade firmada. Nas empresas, a sua atuação é apresentada no que almeja ser trabalhado e desenvolvido de acordo com a realidade do contexto que ela se encontra.

Com ênfase na definição de uma identidade profissional empresarial é válido pautar que, de acordo com as exigências e, também, a complexidade para atuar nas empresas, o pedagogo constrói e reconstrói sua identidade. Ele tem como direção princípios pedagógico que é a essência de suas práticas. 
Assim é possível moldar uma identidade segundo às estruturas estabelecidas pela pedagogia, como cita Libâneo (2001, p.6-7) sobre o acima exposto:

[...] Não há sociedade sem práticas educativas. Pedagogia diz respeito a uma reflexão sistemática sobre o fenômeno educativo, sobre as práticas educativas, para poder ser uma instância orientadora do trabalho educativo. Ou seja, ela não se refere apenas às práticas escolares, mas a um imenso conjunto de outras práticas. O campo do educativo é bastante vasto, uma vez que a educação ocorre em muitos lugares e sob variadas modalidades: na família, no trabalho, na rua, na fábrica, nos meios de comunicação, na política, na escola. De modo que não podemos reduzir a educação ao ensino e nem a Pedagogia aos métodos de ensino. Por consequência, se há uma diversidade de práticas educativas, há também várias pedagogias: a pedagogia familiar, a pedagogia sindical, a pedagogia dos meios de comunicação etc., além, é claro, da pedagogia escolar. (LIBANEO, 2001, p.6-7).

\subsection{O PERFIL ESPERADO DO PEDAGOGO EMPRESARIAL}

O pedagogo empresarial precisa ser proativo, dinâmico, atualizado, criativo, ousado, e principalmente ter conhecimento dos objetivos traçados pela empresa que atua, a fim de alcançar resultados de excelência. Ademais, Ribeiro (2007) complementa que o pedagogo empresarial deve perceber as estratégias que podem ser usadas para que não se desperdice tempos demais aplicando numerosos métodos e com isso perca de vista os propósitos tanto da formação quanto da empresa.

Exige-se do pedagogo uma atuação responsável e sistêmica, já que ele poderá interagir em vários setores da empresa. Atualmente, é necessário que possua uma visão global da empresa. Ou seja, ter uma visão holística com o intuído de se comprometer aos diferentes processos. 
Dessa maneira, é importante que o seu desempenho ocorra de forma relacionada com os demais colaboradores e gestores para alcançar uma comunicação clara e objetiva que busque $o$ atingimento dos resultados esperados.

Contudo, será possível desenvolver e concretizar projetos e traçar ações que colaborem para a melhoria de processos relacionais, funcionais, bem como para melhor o desempenho e progresso da empresa. Assim:

Hoje, com o advento da globalização, a tendência é elevar o gerenciamento de pessoas a uma dimensão mais estratégica, tendo-se uma visão mais sofisticada de administração em parceria com pessoas. Os colaboradores são estimulados a assumir com a direção a responsabilidade de elevar a empresa a atingir seus resultados. (KNAPIK, 2012. p.51)

Logo, as empresas contemporâneas buscam a excelência por meio da contribuição de profissionais com perfil inovador que estejam engajados com os propósitos previstos na organização, além de estarem prontos para qualquer desafio que possa empreender.

\subsection{POSSÍVEIS PRÁtICAS DO PEDAGOGO NA GESTÃO DE PESSOAS}

O pedagogo numa empresa pode atuar na área de gestão de pessoas. É válido enfatizar que se trata de uma vertente compatível com o profissional em lide, pois possuem características intrínsecas de sua formação, ou seja, as estratégias e ações que a pedagogia desenvolve nesses profissionais.

No mundo globalizado e competitivo em que as empresas buscam ser bem sucedidas, apontar e utilizar as estratégias que às coloquem a frente do mercado, é imprescindível. Almeida (2007) afirma que o pedagogo empresarial domina os conhecimentos, técnicas e práticas que somada à experiência dos profissionais de 
outras áreas constituem instrumentos importantes para a atuação na gestão de pessoas.

Um processo no qual o pedagogo pode estar integrado, é no modelo de gestão por competências que se insere no contexto da gestão de pessoas. Este modelo identifica e gera perfis profissionais que possibilita um maior retorno para as organizações. Como demonstra Orlickas (2012) quando propõe que a gestão por competências atue com o objetivo de inovar e tornar as empresas mais competitivas. O modelo de gestão por competência apresenta a sigla CHA (conhecimento, habilidade e atitude). Ainda Orlickas (2012) tal sigla propõe em uma estrutura organizacional, diferem de pessoas para pessoas e formam as competências organizacionais.

As três competências evidenciadas correspondem aos atributos de um indivíduo, referem-se ao conjunto tanto de conhecimentos da própria formação educacional como das habilidades e atitudes adquiridas na função que o indivíduo assume no ambiente de trabalho.

Segundo Takahashi (2015), conhecimento refere-se ao modo como se realizam as tarefas, habilidades como a capacidade na execução das tarefas e atitudes é o comportamento pessoal perante uma tarefa, apontando valores e a própria identidade pessoal. O autor ainda destaca que uma das práticas do modelo por competência é o mapeamento de competência e que para a sua sua elaboração são realizadas entrevistas individuais ou coletivas, questionários, observação de rotinas e reuniões para discussão.

Essas práticas são uma forma de identificar, ou seja, mapear competências existentes e podem ser praticadas pelo pedagogo, pois sua formação aponta estratégias e procedimentos pedagógicos que geram para esse profissional a capacidade em atuar sobre esse mapeamento de competências.

O processo de mapear competências é normalmente realizado pela área de gestão de pessoas em que o pedagogo pode ser empregado para solucionar os desafios desencadeados no dia a dia da empresa, pois permite identificar como o colaborador 
poderá contribuir ou qual função ele terá maior habilidade em executar. Desse modo, Takahashi (2015) pontua que o surgimento de conceito de competência enseja novas práticas de $\mathrm{RH}$ : recrutamento e seleção, planejamento de treinamentos, elaboração de cargos e salários, planejamento de mobilidade funcional, avaliação, entre outras, ou seja, que a atividade do setor de $\mathrm{RH}$ passa a ser do gerenciamento de competências, uma vez que elas geram um desempenho profissional.

\subsection{OUTRAS PRÁTICAS}

Existem processos diversos que são trabalhados dentro das empresas, a partir das práticas de gestão de pessoas, em que a inclusão do Pedagogo pode ser presente. É válido apresentar um fator primordial: pessoas são importantes para que a empresa evolua.

As pessoas e colaboradores são talentos e o capital intelectual do ambiente corporativo que devem ser valorizados e desenvolvidos com objetividade. Conforme cita Orlickas (2012) que independente do propósito e da estrutura organizacional, quando se cria uma empresa, as pessoas devem ser encaradas como componente essencial para o sucesso.

Diversas são as práticas que o Pedagogo poderá aplicar. Diante das ações de gestão de pessoas existem diferentes processos a serem trabalhados, porém é valido ressaltar que cada realidade empresarial pode ser única, ou seja, uma estratégia que é aplicável para uma, pode não ser para outra.

Alguns exemplos de práticas serão apresentados a seguir e acrescidos de informações relevantes. Esses exemplos podem ser praticados pelo pedagogo.

\subsubsection{PLANEJAMENTO DE PESSOAL}

Planejamento de pessoal é a fase inicial na qual se encaminha, planeja pessoas compatíveis com os cargos ou funções desejadas pela empresa. Nas palavras de Scatena (2012), pode-se observar que o planejamento de pessoas consiste em definir qual função ela irá desempenhar, bem como o perfil e sua função. 
A seleção de pessoas certas para o local certo dentro das organizações é o primeiro passo de sucesso. Como existem infinitas habilidades pessoais, as possíveis competências que garantirá sucesso de uma determinada empresa não garantirá um mesmo resultado para outra.

Logo, o planejamento de pessoal é uma etapa fundamental para a indicação dos profissionais com perfil alinhado à realidade da empresa. E o pedagogo pode se unir aos gestores, ajudando na elaboração desse planejamento.

\subsubsection{SELEÇÃO}

Seleção é o processo que permite filtrar e identificar os candidatos, ela "tem por objetivo colocar a pessoa certa no lugar certo por meio da escolha de candidatos que apresentem maiores habilidades". (LOTZ; BURDA, 2015, P. 123).

A prática de seleção consiste no uso de instrumentos para identificar as características dos candidatos, tais quais: técnicas de conhecimento, capacidade, habilidade física, dinâmica de grupo, entre outras. O Pedagogo pode estar à frente dessas atividades.

\subsubsection{TREINAMENTO}

É válido destacar a atuação do pedagogo em relação aos processos de treinamento. De acordo com o contexto histórico, já mencionado no início deste artigo, o treinamento foi uma das primeiras atividades que o pedagogo possivelmente executou no meio empresarial, e pode continuar a executar.

Assim é válido relacionar ao que apresenta ALMEIDA (2006, p. 52):

O papel do Pedagogo Empresarial é apoiar o gestor do desenvolvimento e aplicação das melhores práticas relativas ao desenvolvimento da aprendizagem para os funcionários, principalmente no que se refere aos investimentos para treinamentos, dinâmicas e avaliações que façam diferença na produtividade pessoal e na qualidade de vida no ambiente corporativo. 


\subsubsection{JOGOS EMPRESARIAIS}

O jogo sempre fez parte da vida das pessoas, na infância principalmente, e em outros momentos. Participar de jogos causa divertimento, interação além de provocar momentos de desafios e até de conflitos. E segundo as indagações de Silva e Franco (2018), os jogos estão no dia a dia das pessoas, para cada fase da vida, um ou mais jogos são adaptados. E cita como exemplo, as crianças que gostam de jogar bola; os adolescentes que gostam de jogar videogame; os adultos que gostam de jogar cartas; os idosos gostam de jogar dominó.

Jogos são muito utilizados em ambientes escolares e são bem reconhecidos e aplicados pelo pedagogo nesse meio. Partindo desse contexto é possível, para esse profissional, a capacidade de adaptar, desenvolver e aplicar jogos empresariais. Porém, aqueles aplicados em empresas requerem uma elaboração mais específica, que incluirá outros processos ou outras especificações.

Contudo, para se compreender a maneira em que os jogos empresariais podem ser utilizados como uma ferramenta de ensino e aprendizagem é preciso discutir o efeito dos jogos na vida humana. Para Silva e Franco (2018) os jogos empresariais tentam retratar as possíveis situações que uma empresa e seus competidores podem encontrar no mercado, considerando que a decisão de uma instituição muda o cenário de mercado e impacta nas demais.

Segundo os autores, os jogos nas empresas são aplicados para simular uma situação que possa ser apresentada como um possível desafio a ser enfrentado, tipo uma ação simulada, que engloba situações - problemas, com o intuito dos participantes vivenciarem como se fossem reais, ou seja, um problema ou uma situação que eles, poderão antever, caso aconteça de fato no dia a dia da organização.

O pedagogo empresarial pode contribuir na elaboração e aplicação desses jogos, porém ele deverá estar ciente do contexto que a empresa prioriza, quais os objetivos a serem alcançados, além de ter o apoio de profissionais a frente do setor que terá uma situação simulada. 
No atual mercado altamente competitivo, uma empresa que se prepara para possíveis situações desafiadoras ou que possam gerar problemas, poderá alcançar melhor êxito com atitudes mais assertivas.

\subsubsection{DINÂMICAS}

Dinâmica de grupo é um processo lúdico e que envolve um conjunto de pessoas para refletirem sobre alguma situação ou despertar algo que possa ser importante e que gere reflexão. Segundo Perpétuo; Gonçalves (2005, p. 2):

A dinâmica de grupo constitui um valioso instrumento educacional que pode trabalhar o ensino-aprendizagem quando opta - se por uma concepção de educação que valoriza tanto a teoria quanto a prática $e$ considera todos os envolvidos neste processo como sujeitos.

O pedagogo tem a possibilidade de aplicar uma dinâmica para os colaborados do meio empresarial.

Contudo, para um resultado satisfatório é de suma importância que seja bem planejada e que esteja de acordo com o que as empresas almejam de resultado desse processo. Perpétuo e Gonçalves complementam essa ênfase, considerando que os objetivos específicos de uma determinada estratégia educativa, no sentido de estimular a produção do conhecimento e a recriação deste conhecimento tanto no grupo/coletivo quanto no indivíduo/singular, uma vez que a técnica da dinâmica não é um fim, mas um meio - é uma ferramenta a ser usada.

Dessa forma, realizar dinâmicas nas empresas, será uma maneira de trabalhar várias questões que possam aparecer nesses espaços, pode melhorar as relações interpessoais e a desenvoltura nas habilidades dos profissionais participantes; aumentar a produtividade; ensejar maior comprometimento; estimular a capacidade criativa; entre outros benefícios.

Então, foram apresentadas as práticas do meio empresarial que coadunam com o que o pedagogo poderá atuar: Gestão por competências, práticas diversas de gestão de 
pessoas, jogos empresariais, dinâmicas. Cabe ressaltar que o pedagogo é um profissional capaz de atuar em todas as apresentadas, contribuindo para meios de aprendizagem que alcance resultados de excelência nas empresas.

\section{METODOLOGIA}

Este estudo teve como base uma pesquisa bibliográfica para descrever a atuação do Pedagogo no ambiente empresarial, além de procurar dar ênfase à área de Gestão de pessoas com deferentes atividades apontadas por este segmento de atividades, sendo incluso pesquisas sobre gestão de competências, processos de treinamento, Seleção, planejamento de pessoas, jogos empresariais e dinâmicas.

Portanto foi pesquisado o que são, como são aplicados, quais as finalidades desses assuntos, ou seja, se valendo de uma pesquisa descritiva em que procurou seguir numa linha que consiste coletar, analisar e adquirir informações sobre o presente tema em foco.

Com isso, em sequência, os conteúdos relativos ao tema foram analisados e comparados por meio de diferentes autores e o levantamento bibliográfico teve como importância analisar livros atuais, porém foi interessante se valer de publicações menos contemporâneas para uma comparação enriquecedora do trabalho, assim foi possível apresentar um desenvolvimento coeso e que alcance o objetivo no qual se define a realização e concretização deste Artigo Científico. Dessa forma, Matos e Vieira (2001) caracterizam a importância da pesquisa bibliográfica a partir do levantamento de referências já analisadas, e publicadas por meios escritos e eletrônicos, como livros, artigos científicos e páginas de WEB.

\section{CONSIDERAÇÕES FINAIS}

Este artigo foi elaborado com o propósito em adquirir conhecimentos sobre como foi a inserção do pedagogo na empresa e como são as possíveis práticas desempenhadas. 
Assim, no decorrer do trabalho, que foi produzido por meio de pesquisa bibliográfica, dúvidas foram esclarecidas parcialmente.

Em relação aos objetivos geral e específico, destaco o reconhecimento da inserção do pedagogo; a identificação do perfil esperado e como as empresas visualizam o pedagogo, para esses, os resultados foram satisfatórios.

Já em relação as práticas desempenhadas, dúvidas foram evidenciadas, pois não foi possível concluir de maneira clara em que parâmetro o pedagogo se encontra no contexto empresarial, porém verificou-se que ele pode estar inserido nesse meio empresarial.

Constatou-se que as práticas podem ter grande envolvimento na área de Gestão de Pessoas, o que revelou uma possível atuação do pedagogo.

O presente trabalho poderia ser mais bem esmiuçado se fosse realizada uma pesquisa de campo, observando de perto a realidade vivida nas empresas pelo pedagogo, a fim de reconhecer e comparar com as informações encontradas por meio dos autores estudados.

\section{REFERÊNCIAS}

ALMEIDA, M.G. Pedagogia empresarial: saberes, práticas e referências. $1^{\underline{a}}$ ed. Rio de Janeiro: Brasport, 2006.

CHIAVENATO, Idalberto. Administração de Recursos Humanos. Fundamentos básicos. 8ª ed. São Paulo: Manole, 2016.

DUBAR, C. A socialização e construção das identidades sociais e profissionais. São Paulo: Martins Fontes, 2005. p. 135.

HOLTZ, M. L. M. Lições de Pedagogia Empresarial. Sorocaba- SP, 1999. 
KNAPIK, J. Gestão de pessoas e talentos. 1를 ed, Curitiba: Intersaberes, 2012.

LIBÂNEO, J. C. Pedagogia e pedagogos, para quê? São Paulo: Cortez, 1998.

Pedagogia e pedagogos: inquietações e buscas. Texto de conferência escrito para $\circ 2^{\circ}$ Encontro Cearense de Educadores, promovido pelo OfinArtes - Centro de Acessória Pedagógica, Fortaleza, 1999.

Pedagogia e pedagogos, para quê? $4^{\text {a }}$ ed São Paulo: Cortez, 2001.

Pedagogia e pedagogos: caminhos e perspectivas. São

Paulo: Cortez, 2002.

LOPES, I. Pedagogia empresarial: uma nova visão de aprendizagem nas organizações. Rio de janeiro: wak, 2007.

LOTZ, E. G.; BURDA, J. A. Recrutamento e Seleção de talentos. $1^{\text {a }}$ ed. Curitiba: Intersaberes, 2015.

MATOS, K. S. L.; VIEIRA, S. V. Pesquisa educacional: o prazer de conhecer. Fortaleza: Demócrito Rocha, 2001. 143 p.

ORLICKAS, E. Modelos de Gestão, das teorias da administração à gestão estratégica. $1^{\underline{a}}$ ed. Curitiba: Intersaberes, 2012.

PERPÉTUO, S. C.; GONÇALVEZ, A. M. Dinâmicas de grupos na formação de lideranças. Rio de Janeiro: DP\&A, 2005

PIMENTA, S. G. Saberes pedagógicos e atividade docente. São Paulo: Cortez, 1999

RIBEIRO, Amélia Escotto do Amaral. Pedagogia empresarial: a atuação do pedagogo na empresa. $4^{\mathrm{a}}$ ed. Rio de janeiro: wak, 2007. 
SCATENA, Maria Inês Caserta. Ferramentas para a moderna gestão empresarial, teoria, implementação e prática. 1aㅡ ed. Curitiba: Intersaberes, 2012.

SILVA, Rosinda Angela da; FRANCO, Paulo Roberto. Jogos de empresas: fundamentos para competir. 1르 ed. Curitiba: Intersaberes, 2018.

TAKAHASHI, Adriana Roseli Wunsch. Competências, aprendizagem organizacional e gestão do conhecimento. 1 $^{\text {a }}$ ed. Curitiba: Intersaberes, 2015.

Enviado: Abril, 2020.

Aprovado: Maio, 2020. 